\title{
Diálogos transdisciplinares sobre o corpo a partir da obra de Lygia Clark
}

\author{
Francisco Romão Ferreira \\ Larissa Escarce Bento Wollz
}

racionalização excessiva proposta pela ciência e pela técnica, a partir da
revolução científica moderna, leva a uma ruptura e a uma distinção com-
pleta entre as dimensões racional e afetiva. O homem, subjugado à técnica e ao saber científico, é um homem distante de seus afetos e desejos, afastado de sua percepção sensorial e da criatividade. O conhecimento sobre o próprio corpo, assim como todo saber relativo às áreas humanas, acaba reproduzindo o modelo científico oficial da "ciência natural". Essa alteração do discurso não é apenas uma simples opção por determinado modelo científico; ela traz em si a aposta numa alternativa de construção de conhecimento que permite criar um saber que representa um poder. O discurso científico busca, através de uma prática discursiva, privilegiar determinadas abordagens em detrimento de outras, e desta forma alterar os resultados e a própria concepção de saber. Consequentemente, torna-se uma ferramenta de poder.

Merleau-Ponty (1908-1961) critica essa excessiva racionalização e coloca o corpo, o artista e a obra como partes integrantes de um mesmo movimento. Elimina a oposição entre sujeito e objeto, transformando-os em um único sistema de relações. O corpo deixa de ser um dos polos da oposição entre corpo e mundo para se tornar um entrelaçamento de sensações. Para Merleau-Ponty:

Emprestando seu corpo para o mundo é que o pintor transforma o mundo em pintura. Para compreender estas transubstanciações, há que reencontrar o corpo operante e atual, aquele que não é um pedaço de um pedaço de espaço, um feixe de funções, mas um entrelaçado de visão e de movimento... Tudo 
que vejo por princípio está ao meu alcance, pelo menos ao alcance do meu olhar, assinalado no mapa do "eu posso". Cada um dos mapas é completo. O mundo visível e o mundo dos meus projetos motores são partes totais do mesmo ser... Visível e móvel, meu corpo está no número das coisas, é uma delas, é captado na contextura do mundo, e a sua coesão é de uma coisa. Mas já que vê e se move, ele mantém as coisas em círculo em volta de si; elas são um anexo ou um prolongamento dele mesmo, estão incrustadas na sua carne, fazem parte de sua definição plena, e o mundo é feito do próprio estofo do corpo (Merleau-Ponty, 1975: 135).

Para a fenomenologia, à qual está ligado Merleau-Ponty, o corpo não é apenas um suporte para o sujeito racional, e sua razão de ser não é apenas servir de instrumento para as atividades cognoscitivas e valorativas da razão. Ela entende o corpo (e o sujeito) não como um ser duplo, e sim como uma estrutura única, um sistema integrado em que todas as partes e funções atuam como um todo no movimento geral da existência. Este corpo é um ser-no-mundo que interage com o fluxo dos acontecimentos e faz parte da vida, envolvido e inter-relacionado com outros seres através de modalidades existenciais, e sua participação é temporal e finita. Essas modalidades, que se constituem em maneiras de ser, de se relacionar com o mundo, são, portanto, maneiras de organização das experiências.

O corpo passa a ser então o suporte e a garantia de nossa presença no mundo. É através dele que as experiências se cruzam, se articulam, se dão uma ordem e criam uma hierarquia segundo necessidades e circunstâncias que regem o movimento geral da existência. O corpo é a base. É a estrutura que se constitui na própria existência e se manifesta de forma temporal e finita; é a garantia de nossa presença no mundo e é nele que se manifestam todas as atitudes: sensorial, afetiva, emocional, erótica, intelectual, ou cognoscitiva - enfim, é no corpo que se dão as manifestações fundamentais da nossa vida.

Esta concepção de corpo independe da racionalidade para se estabelecer como única forma de relação com o mundo. Retoma o fundamento da experiência à estrutura corporal e estabelece com o mundo uma atitude cognoscitiva e uma apreensão intelectual do real que não é apenas uma apreensão intelectual que se dá através de conceitos e de uma "explicação" racionalizante. Para Merleau-Ponty (1975), a ação da consciência é uma das modalidades que tem o sujeito para se relacionar com o mundo, mas não é a conditio sine qua non da existência do sujeito mesmo e dos seres. A consciência deixa de ser um poder absoluto para passar a ser uma instância fundada na experiência e uma modalidade interdependente com outras potências que conformam a estrutura corporal.

Pensar o corpo significa, na filosofia de Merleau-Ponty, recuperá-lo na instância que antecede o mundo objetivo. Isto significa querer assumi-lo como ele se 
dá na experiência e no mundo natural, como um ser em seu estado bruto, selvagem, antes que a consciência e o pensamento possam moldá-lo, defini-lo. Recuperar o corpo é localizá-lo, situá-lo e descrevê-lo nas formas primeiras do seu estar, do seu ser no mundo, como sendo prévio da experiência. Vinculada a uma motricidade mais "antiga" que a dirige desde o fundo da sua vida sobre o mundo, como sendo seu motivo, seu destino, sua vocação natural.

É a partir desses princípios que podemos situar alguns dos trabalhos de Lygia Clark. Sua "Nostalgia do corpo" fala justamente desta concepção de consciência cuja experiência antecede a linguagem e o pensamento dito racional. Para ela, a experiência e a consciência estão inscritas no corpo, são rastros, cicatrizes de um tempo não apreensível em conceitos, analisáveis ou explicações racionalizantes. Em seu texto "Breviário sobre o corpo", Lygia afirma que:

Sou da família dos batráquios: através da barriga, vísceras e mãos, me veio toda a percepção sobre o mundo. Não tenho memória, minhas lembranças são sempre relacionadas com percepções passadas, apreendidas pelo sensorial. Num lapso de segundo eu me sinto tomada pela quentura da mamadeira na palma da mão, acompanhada pelo gosto de leite morno que desce devagar, deixando um rastro de bolhas atrás de si. Experiência esta, talvez a mais remota dentro da minha vivência, inscrita no meu passado, que se faz presente ainda hoje (Clark, 1998: 190).

O corpo, para Lygia, é um corpo que fala, pensa e sente. Possui uma memória e uma vivência própria. Lygia, em seus trabalhos, utiliza indiretamente diversos conceitos da psicanálise, e não podemos esquecer que todo o pensamento psicanalítico relativo ao corpo encontra sua origem em Freud (1856-1939). Todos os pensadores que vão atuar nessa área beberam em sua fonte e não é possível entrar nesse território sem fazer referência a ele. Quando falamos de Reich (1897-1957) e nos pós-reichianos, em Winnicott (1896-1971) ou Melanie Klein (1882-1960), não podemos perder de vista que todos criaram suas teorias a partir do pensamento freudiano, são derivações dele. Apesar de alguns autores criarem novas teorias, essas mesmas teorias só se tornaram possíveis em função do caminho aberto por Freud e seus conceitos.

Nos trabalhos de Freud, estão presentes os pressupostos de que o corpo é a fonte básica de toda a experiência mental. Ele afirma que não existe descontinuidade na vida mental, nada acontece por acaso (muito menos os processos mentais), existindo sempre uma causa para cada pensamento, sentimento ou ação, e que nos desejos e no corpo ficam rastros dessa "memória". Esses rastros se cristalizam com o tempo, que para Freud é descontínuo e não obedece à racionalidade. Para ele, existem conexões entre todos os eventos mentais. Deste modo, todos os eventos possuem um "espaço" no inconsciente e podem ser acessados a qualquer momento. 
No inconsciente localizam-se elementos que nunca foram conscientes e que não são acessíveis à consciência. São materiais que foram "excluídos" da consciência, censurados e reprimidos. Mas este material não é esquecido ou perdido, apenas não lhe é permitido ser lembrado. Quando o inconsciente libera memórias para o consciente, estas memórias não perdem nada da sua força emocional, pois os processos mentais inconscientes são atemporais e sua estruturação não é racionalizável. A energia pulsional necessária para administrar as tensões internas obedece a suas próprias leis. Segundo Freud:

Aprendemos pela experiência que os processos mentais inconscientes são em si mesmos "intemporais". Isto significa em primeiro lugar que não são ordenados temporalmente, que o tempo de modo algum os altera, e que a ideia do tempo não lhes pode ser aplicada (Freud,1980a: 41).

A energia pulsional se manifesta através de processos nos quais a energia libidinal disponível na psique é vinculada ou investida na representação mental de uma pessoa, ideia ou coisa. Freud utiliza o termo "catexia", cuja palavra original alemã besetzung significa ocupar ou investir, que é justamente o processo de investimento. Este conceito é criado para instrumentalizar a teoria psicanalítica que está interessada em compreender onde a libido foi catexizada inadequadamente para poder liberá-la ou redirecioná-la, já que a identificação e a canalização da energia psíquica são fundamentais para a compreensão do sujeito na busca de uma possível administração de conflitos e acordos psíquicos. Estes conflitos se dão a partir de pulsões opostas que buscam a supremacia no controle do sujeito.

Para Freud, o foco primário da energia libidinal encontra-se nos vários modos de expressão sexual. A maioria das funções cruciais do corpo está ligada à excitação e diferenciação sexual. A maturidade plena desenvolve-se a partir da plena sexualidade genital. As interações e relacionamentos adultos são fortemente influenciados pelas primeiras experiências infantis. As primeiras relações que ocorrem no seio da família vão ser determinantes na fase adulta, e os relacionamentos afetivos posteriores serão baseados nos efeitos residuais das primeiras experiências. Todo o comportamento emocional e a capacidade intelectual vão também traduzir essas vivências. Os encontros amorosos no decorrer da vida, os padrões de amizade ou casamento vão constituir também uma retomada de facetas não resolvidas nos primórdios da infância. Todo o pensamento psicanalítico posterior que vai produzir um discurso relativo ao corpo parte de alguns desses pressupostos. Mesmo os que buscam negá-los se apoiam nele para articular seus pontos de discordância. As noções relativas à infância do sujeito e suas memórias corporais e/ou afetivas serão derivações mais elaboradas do pensamento freudiano. 
A psicanálise tradicional não dedica muita atenção ao corpo, dando mais ênfase ao conteúdo discursivo, à linguagem, aos lapsos, sonhos - enfim, cria uma dissociação entre corpo e mente. A memória passa a ocupar um lugar dentro desse conteúdo discursivo e só dialoga com o sujeito através da linguagem.

Vale a pena lembrar que a corrente da psicanálise que posteriormente vai trabalhar com o corpo (e que descrevemos a seguir) se situa nos Estados Unidos, no mesmo período em que Lygia produz seus trabalhos na Europa. A tradição psicanalítica francesa (na qual Lygia vai atuar) trabalha preponderantemente com as questões relativas à linguagem e, provavelmente, via simultaneidade de seus trabalhos (com relação aos pós-reichianos) com certa inquietação, sendo que o percurso criado por Lygia com suas obras vai caminhar em uma zona neutra. Eles dialogam e questionam muito mais com o sistema de arte do que com esta tradição psicanalítica. Nos trabalhos relativos à "fantasmática do corpo" e "estruturação do self", Lygia vai abordar vivências corporais que simultaneamente estão sendo trabalhadas por terapeutas corporais (alguns pós-reichianos) de formas diversas.

Wilhelm Reich (1981) enfatiza a natureza sexual das energias e chega a acreditar que a meta da terapia deveria ser a liberação dos bloqueios do corpo e a obtenção da plena capacidade para o orgasmo sexual (que ele acredita bloqueado tanto entre os homens, como entre as mulheres). Para ele, a solução para o trauma psicanalítico pode se dar também através do desenvolvimento da livre expressão de sentimentos sexuais e emocionais dentro de um relacionamento amoroso maduro. A seu ver, o caráter do sujeito se forma como uma defesa contra a ansiedade criada pelos intensos sentimentos sexuais da criança e o consequente medo da punição. A primeira defesa contra este medo é a repressão, que refreia os impulsos sexuais por um tempo. À medida que as defesas do ego se tornam cronicamente ativas e automáticas, elas evoluem para traços de personalidade ou "couraça caracterológica". Reich descobriu que cada atitude de caráter tem uma atitude física correspondente e que o caráter do indivíduo é expresso no corpo em termos de rigidez muscular ou couraça muscular. Ele começou a trabalhar de forma direta no relaxamento nessa couraça e descobriu que a perda de couraça muscular libertava considerável energia libidinal e auxiliava o processo de psicanálise.

Seu trabalho psiquiátrico vai lidar, cada vez mais, com a libertação de emoções (prazer raiva, ansiedade) através do trabalho com o corpo, produzindo com isso uma vivência muito mais intensa do material infantil descoberto na análise. Ele analisava em detalhes a postura de seus pacientes e seus hábitos físicos, a fim de conscientizá-los de como reprimiam sentimentos vitais em diferentes partes do corpo. Ele descobriu que só depois que a emoção "aprisionada" fosse expressa, a tensão crônica poderia ser abandonada por completo. Aos poucos, Reich começou a trabalhar diretamente com suas mãos sobre os músculos tensos, a fim de soltar as emoções presas a eles. A seguir, temos um de seus relatos acerca desta questão.

\section{ALCEU - n.33 - jul./dez. 2016}


$\mathrm{Na}$ análise final eu não poderia livrar-me da impressão de que a rigidez somática representa a parte mais essencial do processo de repressão. Todos os nossos pacientes relatam que atravessaram períodos em sua infância nos quais por meio de certos artifícios sobre o comportamento vegetativo (prender a respiração, aumentar a pressão dos músculos abdominais, etc.), haviam aprendido a anular seus impulsos de ódio, de angústia ou de amor (...) não deixa nunca de ser surpreendente o modo como a dissolução de um espasmo muscular não só libera a energia vegetativa mas, além disso e principalmente, reproduz a lembrança de situação da infância na qual ocorreu a repressão do instinto (Reich, 1982: 254).

Desta forma, Reich descobriu que tensões musculares crônicas servem para bloquear uma das três excitações biológicas - ansiedade, raiva ou excitação sexual - e concluiu que a couraça física e a psicologia eram basicamente a mesma coisa. Para ele, assim que seus pacientes renunciavam à couraça e desenvolviam potência orgástica, muitas áreas de funcionamento neurótico mudavam de forma espontânea. No lugar de rígidos controles neuróticos, os indivíduos desenvolviam uma capacidade de autorregulação. Eles agem de acordo com suas próprias inclinações e sentimentos internos, ao invés de códigos externos ou ordens estabelecidas por outro.

Depois da terapia reichiana, muitos pacientes que antes eram neuroticamente promíscuos desenvolviam grande ternura e sensibilidade, e procuravam, de forma espontânea, relacionamentos mais duráveis e realizadores. Os caracteres genitais não estão aprisionados em suas couraças ou defesas psicológicas. Eles são capazes de se encouraçar, quando necessário, contra um ambiente hostil. Entretanto, sua couraça é feita mais ou menos conscientemente e pode ser dissolvida quando não houver mais necessidade dela. O clímax da atividade sexual é caracterizado pela entrega à experiência sexual e pelo movimento desinibido, involuntário, ao contrário dos movimentos forçados dos indivíduos encouraçados.

Aos poucos, Reich estendeu seu interesse pelo funcionamento físico dos pacientes à pesquisa de laboratório em fisiologia e biologia, e finalmente à pesquisa em física. Ele criou o termo "energia orgônica" a partir de organismo e orgasmo, de modo que a energia orgônica atuasse no organismo como uma energia biológica específica, governando o organismo e expressando-se nas emoções e nos movimentos puramente biofísicos dos órgãos.

Em nossa cultura, é grande a confusão de identidade na maioria das pessoas. A alienação no mundo moderno, do homem, de seu trabalho, de seus companheiros e de si próprio, gera um descompasso entre o sujeito, sua percepção e sua compreensão do mundo. $\mathrm{O}$ amor do indivíduo alienado é romanceado, seu sexo é compulsivo, seu trabalho é mecânico, seus empreendimentos, egoístas. Numa sociedade alienada, essas atividades perdem seu significado pessoal e esta perda é substituída por uma imagem. 
Nesse contexto, o sujeito com identidade em crise eventualmente se utiliza de uma "máscara" ou adota um "papel" como meio de adquirir uma identidade. Quando essa identidade entra em crise, ocorre a cisão entre ego e corpo. Há perda de identificação com o corpo, acompanhada de sensações de estranheza e irrealidade, conhecida como "despersonalização". Esse comportamento demonstra um rompimento com a realidade e, a pessoa perde não só seu sentido de identidade, como também a percepção consciente desta identidade. Para Lowen, o senso de identidade provém de uma sensação de contato com o corpo e, sem essa consciência da sensação e atitudes corporais, a pessoa se torna dividida. A perda completa do contato com o corpo caracteriza o estado de esquizofrenia. Há uma dissociação entre sujeito e realidade, através de um desligamento do mundo, das pessoas e de si mesmo. A perturbação esquizoide gera também a dissociação entre imagem e realidade, em que símbolos e criações mentais se encontram em oposição à realidade da experiência física. O conflito entre o ego e o corpo gera uma cisão na personalidade que afeta todos os aspectos da existência e do comportamento do indivíduo.

Lowen (1971), considerado um dos discípulos de Reich, criou a abordagem da "bioenergética", que é uma das grandes contribuições, tanto teórica quanto prática, da psicologia do corpo. A bioenergética inclui as técnicas reichianas de respiração e muitas das técnicas de Reich de liberação emocional, tais como fazer os pacientes chorarem, gritarem e baterem. Ele também utiliza várias posturas de tensão, a fim de energizar partes do corpo cronicamente tensas até se tornar tão grande que o indivíduo às vezes é forçado a relaxar a couraça. A bioenergética enfatiza também a necessidade de fundamentar-se em seus próprios processos físicos, emocionais e intelectuais. O trabalho, via de regra, se concentra nas pernas e na pélvis, a fim de estabelecer com o solo uma conexão melhor e mais firmemente enraizada. Para ele, essa região é também a base e o suporte para a estrutura do ego (Lowen, 1971).

No decorrer das décadas de 1960 e 70, outras práticas terapêuticas ligadas à psicanálise (que utilizam o corpo como referência) surgem no período em que Lygia apresenta seus trabalhos - entre elas, a "Integração estrutural", também conhecida como "Rolfing", a "Técnica de Alexander", o "Método Feldenkrais", a "Conscientização corporal", o "Despertar sensorial" -, além da revalorização das práticas terapêuticas orientais, como a "Hatha ioga". Interessa-nos a abordagem dessas técnicas.

A "integração estrutural" é um sistema de remodelagem e realiviamento da postura do corpo através de um profundo estiramento muscular realizado pela manipulação direta. Esta técnica e denominada "Rolfing" por causa de sua fundadora, Ida Rolf (1896-1979), que trabalhou por mais de 40 anos no ensino e aperfeiçoamento do sistema de integração estrutural (Fadiman, 1986). O objetivo desse sistema é levar o corpo a um melhor equilíbrio muscular e a um realinhamento em relação à gravidade, buscando uma postura reta e distribuição equilibrada do peso nas principais partes do corpo (cabeça, tórax, pélvis e pernas). O método trabalha primor-

\footnotetext{
194 ALCEU - n.33 - jul./dez. 2016
} 
dialmente com o sistema fascial, o tecido conjuntivo que sustenta e liga os sistemas muscular e esquelético. Rolf salientou que um trauma psicológico ou mesmo danos físicos menores podem resultar em mudanças corporais sutis, porém relativamente permanentes, fazendo com que o "desalinhamento" interfira não apenas na região lesionada, como também em pontos do corpo bastante distantes, como resultado da compensação. O método Rolfing almeja, em primeiro lugar, a integração física e não lida diretamente com os aspectos psicológicos do processo; no entanto, várias pessoas que combinaram o método Rolfing com uma terapia psicológica relataram que o método as ajudou a liberar seus bloqueios psicológicos e emocionais.

A "Técnica de Alexander" é um método para mostrar às pessoas como elas estão usando seus corpos de forma inadequada e ineficiente, e como podem evitar o uso incorreto quando estão em atividade ou repouso. F. Mathias Alexander (1869-1955) foi um ator shakesperiano na Austrália, que passou nove anos auto-observando-se e auto-estudando-se cuidadosamente num espelho de três lados. As lições de Alexander envolvem uma orientação sutil e gradual para o uso mais efetivo e eficiente do corpo. O professor é treinado a detectar os vários modos pelos quais bloqueamos o livre movimento de nossos corpos ou antecipamos o movimento de tensão preliminar e desnecessário. Movendo e reajustando o corpo do estudante aos poucos e de maneira delicada, o professor gradualmente proporciona ao aluno a experiência de repousar e atuar de forma integrada, alinhada e eficiente (Fadiman, 1986). Essa técnica é especialmente popular entre os atores, bailarinos e outros artistas que representam, sendo também usada com grande eficácia em deficientes físicos.

O "Método Feldenkrais" trabalha com padrões de movimento muscular, ajudando o indivíduo a encontrar o modo mais eficiente de se mover, eliminando as tensões musculares desnecessárias e os padrões ineficientes que aprendemos no decurso de anos. Destina-se a ajudar alunos a recuperarem a graça natural e a liberdade das quais desfrutamos todos quando crianças (Fadiman, 1986). Moshe Feldenkrais (1904-1984) doutorou-se em física na França e trabalhou como físico até os 40 anos de idade. Interessou-se por judô e fundou a primeira escola do gênero na Europa. Trabalhou também com F. Mathias Alexander e estudou ioga, Freud, Gurdjieff e neurologia, dedicando-se, após a Segunda Guerra, ao trabalho com o corpo. Em seu método, os movimentos começam muito pequenos e gradualmente vão se combinando em padrões mais amplos e complexos. O objetivo é desenvolver facilidade e liberdade de movimentos em todas as partes do corpo. Ele observou que o sistema nervoso está intimamente relacionado com o movimento e que os padrões de movimento refletem o estado do sistema nervoso. Feldenkrais procurou restabelecer as conexões entre o córtex motor e a musculatura, conexões que entraram em curto circuito ou foram desviadas por maus hábitos, tensão ou outras influências negativas. O objetivo é desenvolver um corpo que possa se mover com um esforço mínimo e o máximo de eficiência, não através da força muscular, mas da 
maior compreensão do funcionamento corporal, possibilitando maiores consciência e flexibilidade, alcançadas por meio de equilíbrio e tranquilização do córtex motor. Ao equilibrar o córtex motor e reduzir o nível de excitação, ele descobriu que podemos expandir tremendamente nossa consciência e que nos tornamos capazes de tentar novas combinações de movimentos que não eram possíveis quando as conexões eram presas a padrões circunscritos e limitados (Fadiman, 1986).

A "Conscientização sensorial" é um sistema ensinado nos Estados Unidos por Charlote Selver (1901-2003). Trata-se de um processo de aprendizagem para voltarmos a entrar em contato com nossos corpos e nossos sentidos, uma habilidade que todos possuíamos quando crianças, mas perdemos no decorrer da infância e educação formal. O trabalho de conscientização sensorial focaliza a percepção direta, ensinando a distinguir as sensações das imagens apreendidas cultural e socialmente e que com grande frequência encobrem e distorcem nossa experiência (Fadiman, 1986). Selver salienta que, na medida em que uma quietude interior se desenvolve gradualmente, a tensão e a atividade desnecessárias diminuem, e a receptividade a processos internos e externos intensifica-se. Pressão e afobamento se transformam em liberdade para velocidade, e outras mudanças ocorrem ao mesmo tempo na pessoa toda.

O "Despertar sensorial" baseia-se em um dos livros do "movimento do potencial humano", Sense relaxation below your mind, de 1968, que foi escrito por Bernard Gunther e fez muito sucesso quando foi lançado. O livro baseia-se em workshops orientados para os sentidos e inclui uma variedade de exercícios planejados para que as pessoas entrem em contato com seus corpos e sentidos, aprendam a aceitar a tocar e ser tocadas, a proteger e ser protegidas (Fadiman, 1986). Os exercícios do "Despertar sensorial" incluem dar pancadinhas suaves no próprio corpo, bater levemente ou tocar outros, esticar, massagear, saborear. Esses exercícios nos compõem em si mesmos um sistema de crescimento, mas parecem ser mais eficazes como atividade de aquecimento para desenvolver um senso de intimidade e confiança num grupo de desconhecidos. Podem também ser úteis quando as pessoas estão num impasse intelectual ou emocional, na medida em que o fato de trabalhar com o corpo e com os sentidos pode frequentemente fazer com que elas saiam do impasse.

O sistema conhecido por "Hatha ioga" enfatiza um grande número de práticas e disciplinas destinadas a controlar o corpo e as pranas (ou energias vitais do corpo). Seu objetivo principal é desenvolver um funcionamento corporal saudável e apropriado, e um dos seus maiores propósitos é purificar e fortalecer o corpo enquanto veículo para vários tipos de energias vitais. Para a Hatha ioga, existem cinco formas de energia vital, que lidam principalmente com: respiração, digestão, eliminação, circulação e cristalização. Muitas de suas práticas destinam-se a purificar os nadis (pequenos canais do corpo onde correm as energias vitais) que foram obstruídos devido a uma alimentação falha e a padrões de vida impróprios. Seus ensinamentos 
referentes à dieta e jejum e outras técnicas de respiração se destinam a promover um fluxo livre de energia no corpo.

Todos os sistemas tratados aqui se referem ao corpo e à mente como um todo, um ser único, e uma mudança em qualquer nível iria afetar as outras partes. Mas cada um desses sistemas aparentemente vai especializar-se numa área diferente do funcionamento físico. $\mathrm{O}$ trabalho reichiano e bioenergético lida com bloqueios corporais emocionalmente carregados, enquanto que o método rolfing trabalha para reestruturar os desalinhamentos do corpo, que podem ser causados por danos físicos ou outros fatores. O trabalho de Alexander enfoca o uso do corpo mais do que a estrutura, e o método Feldenkrais também lida com o uso. A conscientização sensorial e o relaxamento dos sentidos enfocam esses mesmos sentimentos, que visam tornar o sujeito mais consciente do corpo e da realidade. Da mesma forma, a Hatha ioga é uma disciplina de fortalecimento e purificação do corpo.

Podemos pensar em algum tipo de sincronicidade que leva esses trabalhos a se desenvolverem de forma simultânea ao trabalho de Lygia. As décadas de 1960 e 70 são conhecidas por seu potencial revolucionário e realmente são inúmeras as transformações ocorridas nas esferas política, cultural, comportamental. Não é por acaso que nesse momento acontece uma grande revolução sexual e, consequentemente, uma grande valorização das questões do corpo. Ao trabalhar com o corpo, Lygia está dentro do sistema de arte e as transformações ocorridas no seu trabalho traduzem uma lógica interna, própria ao desenvolvimento de seu sistema de pensamento. Lygia chega ao corpo como uma consequência natural do seu percurso.

No panorama cultural e no sistema de arte, são também inúmeras as transformações nesse período, e não é por acaso que surgem as performances, a body art e os hapennings nesse contexto. Como veremos a seguir, esta "participação" do corpo não é recente, mas nesse período ela ganha impulso, colocando o corpo no centro da discussão. A utilização do corpo humano em rituais religiosos e culturais remonta às origens da civilização, e podemos encontrar vestígios dessa utilização em rituais tribais de várias culturas. Em nosso século, não podemos deixar de citar as experiências futuristas e dadaístas que utilizavam a performance como um meio de provocação para o público e também como forma de romper com a arte tradicional e impor novas formas de arte. "O que se buscava era uma vasta abertura entre as formas de expressão artística, diminuindo, de um lado, a distância entre vida e morte, e por outro lado, que os artistas se convertessem em mediadores de um processo social" (Glusberg, 1987: 12).

$\mathrm{Na}$ segunda metade do século, surgem movimentos de vanguarda que vão utilizar o corpo como suporte e meio da obra, e procurar desfetichizar o corpo. A body art vai se diluir em um gênero mais amplo, a performance, que centra suas atividades no corpo, exaltando suas qualidades plásticas, medindo sua resistência e energia, desvelando seus pudores e inibições sexuais, examinando seus mecanismos 
internos, seu potencial para a perversidade e seus poderes gestuais. Serve de base também para situações exteriores, como esculturas vivas, experiências com figurinos, cerimônias litúrgicas, ações andróginas, investigações sobre as relações com o espaço, a relação com o artista e o público, os fenômenos perceptivos, telepáticos e oníricos, além de enfocar temas sociais como alienação, solidão, massificação e declínio espiritual. Outras referências são as relações com o teatro e a dança, buscando a desarticulação de seus mecanismos clássicos, e também algumas propostas ligadas à fonética e ensaios linguísticos.

A década de 1970 é marcada por essas experiências, com um grande número de eventos acontecendo em países como Canadá, Estados Unidos, França, Inglaterra, Itália, Holanda, Alemanha Ocidental, Japão e alguns latino-americanos. Um grande número de artistas se engaja nessa forma de arte e cria diversas influências no teatro, na música e na dança. São várias as formas de utilização do corpo nesses eventos, mas o enfoque será dirigido às ações aparentemente banais ou movimentos, gestos, atitudes e ações interpessoais, em que podemos perceber convenções determinadas pela cultura ou por algum tipo de regra social, que permitem o estabelecimento de uma leitura semiótica acerca do corpo humano. Isto se dá através de disciplinas como teoria da gestualidade, cinética corporal, análise da gesticulação natural e cultural, da mobilidade e motricidade, gesticulação mítica, comunicação gestual, mimética, lúdica e outras abordagens ligadas à semiótica. As performances vão atuar nesta área, criando ou desconstruindo condicionamentos gestuais cotidianos, demonstrando a "naturalidade" de certas ações, decodificando movimentos, gestos, comportamentos e gestos fisionômicos impostos pela cultura.

Trata-se de uma metalinguagem que trabalha com o discurso do corpo através da observação e o ressignifica, ou seja, agrega novos significantes a ele. Desfaz a ilusão de um corpo desprovido de significado em suas ações "naturais" e "normais", e valoriza a prática corporal, que antes se encontrava alienada, impossibilitada de entender seus comportamentos habituais. Cria uma perspectiva multidisciplinar ao analisar estes programas comportamentais complexos que tocam a interioridade do sujeito e põe em crise sua estabilidade fundamentada na repetição normalizada de convenções gestuais e comportamentais.

\section{Considerações finais}

Os trabalhos de Lygia Clark traduzem esse período e incorporam pensamentos oriundos da psicologia da forma (Gestaltpsycologie). Ela vai aos poucos se modificando e perdendo o caráter excessivamente racionalista que marca os trabalhos construtivos, que buscam a aproximação da pesquisa estética com a pesquisa cientifica pura. Ela incorpora o pensamento topológico e se aproxima de uma concepção fenomenológica de tempo e espaço; incorpora também o existencialismo e sua "consciência" 
de "existência e reflexão", voltados para o sujeito e para a construção do "sentido" para uma existência autêntica. Ela atua nesta fronteira imprecisa onde os saberes, técnicas, ciência, pensamento, politica, ética e cultura se encontram. Incorpora a subjetividade e possibilita uma significação emotiva e existencial para os conceitos de forma, espaço, tempo e estrutura da obra. Passa a solicitar do espectador não apenas uma postura passiva de estímulo e refluxo de forma mecânica. Propõe, no entanto, resgatar o pensamento através do olhar, trazendo à tona a sensibilidade do espectador. O suporte deixa de ser passivo para se transformar no próprio meio de expressão, deslocando o pensamento plástico do plano para o espaço e posteriormente para o próprio sujeito fruidor.

O espectador é convidado a participar da construção dessa nova obra de arte que nega a tradição imóvel, ideal e eterna. Ele passa a "vivenciar" a obra, conhecê-la nas suas novas dimensões espaciais, temporais e estruturais. É a percepção fenomenológica que não aceita a divisão entre pensamento e sensibilidade, sujeito e objeto, arte e vida. Lygia faz com que o espectador crie novas relações com o próprio corpo, demonstrando suas ambiguidades constitutivas. Esse espectador, que a princípio apenas participa e interage com as obras, no momento seguinte é convidado a se constituir na própria obra. Seu corpo é incorporado, trazendo suas memórias e vivências, chegando a "tocar" no inconsciente por intermédio de sua memória "sensorial" em busca da "Nostalgia do corpo".

As obras de Lygia acompanham as transformações que sofrem as áreas do pensamento nos anos 1960 e 70. São grandes transformações na sociedade, na cultura, no campo da arte, na ciência e no pensamento filosófico que vão atravessar seu trabalho. Nessas mudanças, estão presentes a tentativa de eliminar, ou pelo menos diminuir, a distância entre arte e vida, e nelas, a postura do espectador e sua relação com seu próprio corpo e destino vão ser radicalmente transformadas. O corpo, cuja concepção já vem sendo "transformada" desde os primeiros pensadores, passa agora a se constituir na base e estrutura da existência, onde se manifestam as atitudes sensorial, afetiva, emocional, erótica, intelectual, cognoscitiva e até política. Enfim, é no corpo que se operam as transformações do sujeito em seu tempo e é a partir do uso que faz dele que o sujeito constrói sua existência no mundo.

Para Lygia, o corpo fala, pensa e sente. Possui uma memória e uma vivência própria. O que ela denomina como a "Nostalgia do corpo" pertence a um território corporal que só pode ser acessado pelo sensorial, já que sua "memória" antecede a linguagem e o pensamento racional. No mesmo período, as artes plásticas são marcadas por um grande número de acontecimentos que utilizam o corpo como referência principal. O corpo passa a servir de base para se transformar em esculturas vivas, experiências com figurinos, cerimônias litúrgicas, ações andróginas, investigações sobre as relações com o espaço, a relação entre o artista e o público, o estudo dos fenômenos perceptivos, telepáticos e oníricos, além de trabalhar com 
temas sociais, como alienação, solidão, massificação e declínio espiritual. O corpo vai ser exaltado em suas qualidades plásticas, avaliado em sua resistência e energia, vai ter seus pudores e inibições sexuais revelados, será examinado em seus mecanismos internos, seu potencial para a perversidade e seus poderes gestuais. Enfim, o corpo vai ser "ressignificado" nos anos 1960 e 70, permitindo ao sujeito criar novos modos de existir.

São experiências táteis, motoras, acústicas, cenestésicas, visuais, olfativas, algumas até míticas, eróticas -, enfim, o corpo é modelado, ritualizado, inserido no conjunto da arte contemporânea, criando e percebendo sentidos, ou ainda, agindo como um instrumento de comunicação e significado. Pois é nesse contexto onde se misturam fenomenologia, existencialismo, práticas terapêuticas centradas no corpo, revolução sexual, contracultura, happenings, performances, movimento hippie, experimentações na música, no teatro, na dança, tropicalismo, valorização da cultura oriental - enfim, eventos simultâneos que vão fazer parte do caldeirão cultural onde Lygia vai atuar, produzir sua revolução pessoal, e consequentemente, uma transformação no sistema de arte no Brasil. Mas não podemos esquecer que o ponto de partida é o objeto mais simples, único e original que nos constitui, o nosso próprio corpo e nossas memórias afetivas/inconscientes.

Francisco Romão Ferreira Professor da Universidade do Estado do Rio de Janeiro (UERJ) e da Fundação Oswaldo Cruz (IOC/FIOCRUZ) chico.romao@yahoo.com.br

Larissa Escarce Bento Wollz Psicóloga do Ministério Público do Estado do Rio de Janeiro (MPRJ) lwollz@yahoo.com.br

Recebido em maio de 2015.

Aceito em setembro de 2015.

\section{Referências}

CLARK, L. Catálogo geral. Barcelona: Fundació Antoni Tápies, 1998.

FADIMAN, J. e FRAGER, R. Teorias da personalidade. São Paulo: Harbra, 1986.

FREUD, S. Além do princípio do prazer. In: Edições Standard, v. XVIII, Livro

13. Rio de Janeiro: Imago, 1980a. Novas conferências introdutórias sobre a psicanálise. In: Edições

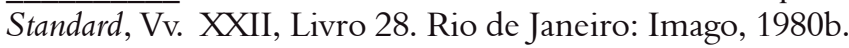

de Janeiro: Imago: 1980c. . Esboço de psicanálise. In: . Edições Standard, v. XXIII, Livro 7. Rio

GLUSBERG, J. A arte da performance. São Paulo: Perspectiva, 1987. 
LOWEN, A. The language of the body. New York: MacMillan, 1971.

MERLEAU-PONTY, M. O olho e o espírito. In: Coleção Os pensadores. São Paulo: Abril, 1975. REICH, W. A função do orgasmo. São Paulo: Brasiliense, 1981. . A revolução sexual. Rio de Janeiro: Zahar, 1982.

\section{Resumo}

Este texto trata dos trabalhos de Lygia Clark que se referem à "Nostalgia do corpo". Essas obras incluem o corpo do participante, que antes era um mero espectador, e é no contato com o corpo que a obra vai se realizar. Esse espectador que contempla a obra de arte e faz parte da audiência do sistema de arte também sofreu inúmeras transformações culturais, éticas e políticas no mesmo período que ela produz suas obras. As mudanças com relação ao próprio corpo (através da cultura e da ciência) e as relações do sistema de arte com o corpo (do artista e/ou do espectador) são contemporâneas às transformações dos grandes sistemas de produção de conhecimento. Interessa-nos, neste estudo, abordar algumas dessas mudanças e relacionar essas transformações do estatuto do corpo com a obra de Lygia Clark.

\section{Palavras-chave}

Corpo. Nostalgia do corpo. Terapia do corpo. Arte. Cultura.

\section{Abstract}

Interdisciplinary dialogues on the body from Lygia Clark's work

This paper deals with Lygia Clark's works that refer to the "Nostalgia body". These works will include the participant's body, which was once a mere spectator, and it is in contact with the body that the work will take place. This viewer who contemplates the work of art, and is part of the art system hearing, also suffered several cultural, ethical and political transformations in the same period she produced her works. The changes concerning the body itself (through culture and science) and the relationship of the art system with the body (artist and / or viewer) are the transformations of the great contemporary systems of knowledge production. In this study we are interested in addressing some of these changes and relate these body status changes with the work of Lygia Clark.

\section{Keywords}

Body. Body nostalgia. Body therapy. Art. Culture. 